\title{
Llosa Vélez, Pedro (2017). La medida de todas las cosas. Lima: Emecé Cruz del Sur.
}

El título del libro recuerda las inmensas dificultades de comprender el célebre apotegma de Protágoras. Incluso, atribuir al hombre como la vara de medición absoluta es todo un reto. Más es un enigma que una proposición. Algunos han llevado esta afirmación a leerla desde claves relativistas. Es decir, cada individuo tendría un margen amplio de interpretar las cosas. Es evidente que si uno sigue esta lógica, cualquier punto de intersección sería casi imposible. Sin embargo, es verdad que la manera cómo se ve el mundo pertenece a ámbitos estrictamente personales. Uno oscila entre patrones de lectura consensuados, acaso desde sus propias y muy particulares claves de explicarse lo que sucede. En ese itinerario es que se va desplegando cada uno de los seis formidables cuentos de Pedro Llosa. El bloque inicial está compuesto de tres historias alrededor de las relaciones de pareja.

El primer cuento titulado "Unas fotografías, apenas" tiene una versión anterior que había obtenido el premio Copé de bronce en el año 2014 y había sido publicado en el compilado que edita PetroPerú con sus ganadores y finalistas literarios. Iniciar el volumen con esta melancólica historia de amor marca el tono de los siguientes relatos. Además, la obertura con una cita de Onetti no es gratuita. Llosa acepta el mapa emocional del escritor uruguayo pero le quita el nihilismo. El protagonista, un conflictuado profesor de política global (que usa la reflexión en sus clases como contrapunto) descubre, entre los viejos papeles de su pareja, una serie de fotografías de la complaciente mujer con su anterior amante. Este develamiento de un pasado erótico compartido dispara una compleja implosión emotiva. Ante una situación de esa dimensión, la reacción puede ser simplemente de una aceptación resignada o incluso espontáneamente cínica de los acontecimientos pasados. Pero, insistimos, cada ser procesa los sucesos de manera distinta. En este caso, el estallido va revelando una crisis amorosa 
que no había sido explícita, acaso escondida, en el protocolo burocrático de la cotidianidad. Es decir, no era tan importante saber el pasado amoroso en sí mismo, entendiendo que las experiencias contemplan justamente una variedad de posibilidades emparejadas, sino la conservación de un catálogo gráfico de una historia de amor en la que no formaba parte. Más que la historia expuesta era el recuerdo impreso, ordenado, resguardado después de tantos años, con un guion secreto que ofendía. Las fotografías hacían persistente una realidad aparentemente ida. El olvido era resarcido por el archivo visual. No son unas fotografías, apenas, sino el detenimiento de un fragmento de lo real, estancado en el tiempo, sobreviviendo. Y justamente esa perseverancia es la que injuria: "Él exigía alguna explicación, alguna historia, algún argumento, algo que le trajera sosiego: ¿Por qué la inmortalización de momentos que de por sí son mortales si no es para desear que se repitan? ¿Para revivirlos en la imaginación?” (p. 26). Ese vestigio de la realidad no es inocuo, contiene un grado de sobrevivencia que afecta el presente. Por otro lado, el escenario que sirve de contrapeso, y es la línea argumental para explicar la alternativa final, es el debate en las aulas. El protagonista despliega a Hobbes y a Platón para explicar la realidad peruana, mientras su lado más libidinoso va acercándose a la contemplación de una de sus alumnas. La joven se entrega con inocencia conceptual. Así puede comprenderse que la vía política trazada hobbesianamente, Homo homini lupus, según reza la máxima latina, también se va dimensionando en la vida íntima. La política no solo existe en los exteriores, sino en la vida familiar. Hobbes se expresa en la cama. De ese modo, cada vinculación siempre está al borde de la destrucción y, para evitarlo, o se hace política o existe el amor. Ergo, es lo mismo, finalmente. Ello lleva a seguir una regla de juego de la órbita política y a la vez de cortejo, la joven estudiante entusiasmada, va consintiendo una nueva historia, transgresora, discreta, alejada, una forma de redención.

"Alboradas" es el segundo cuento y esta vez la pareja disputa el lugar para vivir: o Madrid, con su serena aventura y zonas de gozo permanente, o la helada Róterdam y su igual de fría escuela de filosofía analítica donde, el aspirante 
a filósofo, intenta sustentar una tesis de maestría a contrapelo del paradigma teórico dominante. Él, estudiante que cuestiona entusiastamente los modelos de aprehensión; ella, entregada al amor posible y con totalidad, quiere retenerlo, acoplarlo, amarlo. Para asumir la devoción total debe darse una vida junta y sin posibilidades de una puerta de escape. En efecto, el primer escenario es que luego de su sustentación continúe el doctorado en esa ciudad polar, casi compuesto de proposiciones lógicas, pero ello significaría un alejamiento que más allá de la buena voluntad es una forma de separación. Y es ahí donde se filtra la probabilidad de la ruptura, del término, del fin. Es un dilema, entonces. Difícil ante la esperanza de un plan vital conjunto, de una agenda cotidiana común, de una convivencia como ejemplo de felicidad. Esa antinomia a resolver es todo un reto sentimental. Elegir el instante de dicha y sus contradicciones que ofrece la coexistencia diaria. O la línea de una ruta académica, complementada con ese romance naciente. Sin embargo, la resolución no viene por una opción emotiva o una toma de decisión de profundo debate interno, en eso Llosa es brillantemente sutil.

El tercer relato tiene una espectacularidad en el sentido del pulso desarrollado y las tácticas narrativas. Esta vez el verso de Rilke marca el universo: "La única patria de todo hombre es su infancia". Usando como marco la estrategia argumental del marxista analítico Cohen, quien tiene un texto contundente titulado Si eres igualitarista ¿cómo es que eres tan rico? (Barcelona: Paidós, 2001), el protagonista va hilvanando y reconstituyendo su propia vida a propósito de los cazadores de ostras y las aves ostreras monógamas cuyo nombre da título al cuento. Asimismo, se ubica en una posición de privilegio de clase, por lo que incluso el discurrir de la historia es en una playa privada, la cual antes era de acceso público y gratuito. Esta frontera entre el mar y la tierra estaba vinculada a su pasado infantil de felicidad plena sin distingo de riqueza material o étnica. Un campamento cuya equidad era la metáfora de una utopía. Pero también de un estadio social anhelado y necesario. La evolución cada vez más extrema de la desigualdad entre ricos y pobres, acaso solo unidos por una aproximación meramente teorética pero inconmensurable mientras va preparando una ruptura 
amorosa con esos mismos instrumentos académicos. De esta manera, el núcleo ideológico tiene una función vital, es bajo ese paraguas que se toma las decisiones. Ello incluye necesariamente la misma vida de pareja. No se podría vivir siendo tan antagónicos ideológicamente por más que la situación de clase sea análoga. De ese modo, la elección de una vida conjunta será posible en tanto se comparte una visión de mundo más equitativo y justo. Eso complica el noviazgo con una persona totalmente opuesta a siquiera imaginar un mundo organizado y sin clases. Es evidente lo que sigue ante tamaño abismo de concepción.

El bloque siguiente, compuesto de otros tres cuentos, cambia a historias aún más glosadas por disputas ideológicas. "El juglar de feria" es una venganza pública y argumentada sobre un espécimen de la derecha más cavernaria. El epígrafe de José Carlos Mariátegui, a propósito del iluminador talento de César Vallejo, otra vez marca el acento del cáustico relato. El vate más importante del Perú es acusado por un señor llamado Antonio Landaure, empresario e ignorantemente audaz, de ser el causante de las hondas angustias nacionales. En alucinante silogismo, publicado en el diario más antiguo del país (y basado en un caso real), este columnista sostiene que: "Vallejo... dejó un influjo nefasto y destructivo en el inconsciente de todos los peruanos" (p. 135) y de pasada coloca también a Julio Ramón Ribeyro como otro de los culpables de nuestras desgracias y pesadumbres colectivas. Para ello, con ímpetu escolar, cita al liberal Von Mises como su fuente de legitimidad académica. A través de los ojos cada vez más complicados del editor de la sección del tabloide, aupado por una vaga agenda liberal, hace oídos sordos de los consejos sensatos para no publicar la columna de marras. El publicar ese rebuzno inicia el desmoronamiento tanto de su propio estatus profesional como de la soledad apenas aceptada de sus asuntos amorosos. Cuando el vergonzoso texto de Landaure comienza a ser desmembrado por los intelectuales y periodistas más prestigiosos es que percibe que su defensa del statu quo estaba sobre arena movediza. Llosa cuenta, y con placer, el minucioso desmontaje de la atrevida ignorancia de un representante del oponente ideológico tirado para el lado conservador. Es un ajuste de cuentas demoledor. 
El quinto cuento, "El príncipe de la basura", es un homenaje al estilo de Julio Ramón Ribeyro, quien es citado como epígrafe también. Incluso, por la propia configuración de los personajes, el lenguaje es procaz, callejero y con ritmo más oral. A diferencia del fraseo de los anteriores cuentos, este tiene una cadencia más trepidante. Es sobre unos personajes socialmente marginales que dentro de los barrios más pudientes recogen la basura como un medio de sobrevivencia: el llamado "Príncipe". Sobre la trayectoria de este personaje y su final trágico es que va enhebrando el sino del fracasado y su derrota. Es decir, hay mundos paralelos a la vida disforzada y despreocupada de los que viven en los departamentos miraflorinos. Hay todo un hábitat de supervivencia. Estos recicladores tienen sus propios códigos y ambiciones. Eso incluye la posibilidad de hacer negocios con la basura. Parece un pleonasmo pero, en el Perú, la basura es abundante. Esa posibilidad de emprendimiento esconde un formato equitativo a su objeto empresarial. Mientras algunos escarban en la bazofia, otros quieren aprovechar ello, pero las autoridades del distrito contemplan modernizar el sistema de recojo. Para ello un holandés, experto en el asunto, trae nueva tecnología. Las pequeñas historias comienzan a confluir en la imposibilidad. Por eso es tan ribeyriano. Las coincidencias descalabran los planes. La maestría de Llosa para hacerlos confluir con naturalidad hace de este relato un ejemplo de las técnicas usadas. El final de este cuento es un ejemplo contundente de lo que suele suceder en nuestro país.

El último cuento titula "La medida de las cosas". Protágoras aparece en la dimensión del sofista que esperaba una remuneración por sus conocimientos. Algo tan elemental ahora. La historia es sobre los negros literarios. Llosa es implacable en su juicio ante la fagocitación del escritor por los poderosos. Además, como cualquier profesión, la escritura es factible de negociar y más, al parecer, si permite sacar de la pobreza a un anónimo talentoso. De ese modo, el autor mercenario no tiene remilgos en vender su capacidad al mejor postor. Por supuesto, puede autolegitimarse con razones de índole moral, pero los resultados son los mismos. Es la claudicación total ante una posición defensora de una ética de los escritores. Eso, al parecer, sea cual fuere la situación del autor posible, forma parte de la dinámica del mercado. 
Finalmente, este conjunto de relatos pone a Pedro Llosa en la primera línea de la narrativa peruana última que ha traído una renovación tanto de las tácticas escriturales como de la temática alejada de la endogamia y las aburridas literaturas del yo. Su profundidad cala las capas que van enroscándose para ofrecernos, a propósito de un catálogo imponente de filósofos y economistas, momentos aparentemente habituales pero que son resultado de una complejidad discursiva y sentimental. Hay de trasfondo una tensión ideológica en la cual toma parte inteligentemente. Esa toma de posición, perspicaz y admirable, es inevitable en unas circunstancias políticas y literarias enemigas de la lucidez. Estos relatos recogen lo mejor de nuestra tradición cuentística peruana y amplían sus posibilidades.

\section{Rubén Quiroz Ávila}

Universidad Nacional Mayor de San Marcos, Lima, Perú

Contacto: rquiroza@unmsm.edu.pe

https://orcid.org/0000-0002-6152-038X 